Preface

\title{
Emerging Paradigms of Thrombosis and Cancer (Part I): The yin yang Relationship between Thrombosis and Cancer
}

\author{
Hau C. Kwaan, MD, FRCP ${ }^{1}$ Paul F. Lindholm, MD ${ }^{2}$ \\ ${ }^{1}$ Division of Hematology/Oncology, Feinberg School of Medicine, \\ Northwestern University, Chicago, Illinois \\ 2 Department of Pathology, Feinberg School of Medicine, \\ Northwestern University, Chicago, Illinois
}

Semin Thromb Hemost 2019;45:319-320.

The association between thrombosis and cancer was first brought to our attention by Trousseau's teaching, when he lectured on "phlegmasia alba dolens" in three of his patients with gastric cancer. ${ }^{1}$ Since then, we have confirmed that many thrombogenic factors can lead to cancer-associated thrombosis. Alternatively, fibrin and many hemostatic factors can also promote carcinogenesis. One of the earliest observations on the presence of tumor cells in fibrin was made by Billroth, ${ }^{2}$ who believed that fibrin plays an important role by which tumors spread. Since then, a causal relationship between fibrinogen, thrombin, or platelets and cancer growth and metastasis has been established by many observations. As a result, there have been numerous attempts to control tumor growth by inhibition of these hemostatic factors. Thus, there appears to be a complex reciprocal interrelationship between cancer and thrombosis.

In this issue of Seminars in Thrombosis and Hemostasis, our invited contributors give our readers their expert views on both aspects. The articles being written under this theme are actually appearing in two issues of this journal. Part I (the current issue) begins with an exploration of the thrombogenicity of cancer, as Mahajan et al present a review examining epidemiologic findings of venous thromboembolism in cancer. ${ }^{3}$ Within the wide spectrum of cancers, perhaps glioma is one of the most thrombogenic cancer types, as next discussed by Czap et al. ${ }^{4}$ Risk factor for thrombosis in brain tumors is discussed next by Riedl and Ay, with interesting recent findings that podoplanin plays a key role. ${ }^{5}$ More severe thrombotic manifestations are frequently presented as disseminated intravascular coagulation, the many forms of which are therefore discussed by Levi. ${ }^{6}$ Another significant manifestation of the coagulopathy seen in cancer is "cancerassociated thrombotic microangiopathy" as discussed by Weitz. ${ }^{7}$ The diagnostic characteristics of cancer-associated thrombosis can be assessed by a variety of means, including

Address for correspondence Hau C. Kwaan, MD, FRCP, Division Paradigms of Thrombosis and of Hematology/Oncology, Feinberg School of Medicine, Northwestern University, Chicago, IL (e-mail: h-kwaan@ northwestern.edu).
Cancer-Part I; Guest Editors: Ha C. Kwaan, MD, PhD, and Paul F. Lindholm, MD. viscoelastography. This new diagnostic approach is championed by Walsh et al. ${ }^{8}$ They point out the similarity and differences between the coagulopathies seen in acute trauma and malignancy-associated coagulopathy, using this particular technique.

Following this, several other authors present their views on how hemostatic factors may enhance tumor growth and metastasis, beginning with a discussion of the interesting relationship between oncogenes and clotting factors by Tawil et al. ${ }^{9}$ Different views on the role of tissue factor in cancer are then presented by Hisada and Mackman ${ }^{10}$ and by Rondon et al. ${ }^{11}$ This issue of the journal is completed by a review of the role of fibrin and fibrinolysis by Kwaan and Lindholm. ${ }^{12}$

Part II of this theme compendium on thrombosis and cancer will be presented at a future date. Part II will contain other topics on both aspects of this interaction between thrombosis and carcinogenesis. There will be articles that provide further evidence that fibrinogen and platelets can promote carcinogenesis, as well as factors in fibrin gel that enhance angiogenesis. The role of tumor-induced vascular permeability and angiogenesis on coagulation factor and fibrinogen extravasation on protumorigenic stroma formation will also be presented. At the same time, other articles will cover the new approach to management of cancerassociated thrombosis with direct oral anticoagulants. Anticoagulants are not without risks, and thus the risk-benefit considerations will also presented.

Although there have been prior issues of Seminars in Thrombosis and Hemostasis on the topic of cancer and thrombosis, the present compendium represents a novel compilation. We are most excited in assembling these articles in two issues of the journal, and believe that they will provide our readership with a balanced view of the reciprocal and interdependent relationship between cancer and thrombosis.
Copyright $\odot 2019$ by Thieme Medical Publishers, Inc., 333 Seventh Avenue, New York, NY 10001, USA. Tel: +1(212) 584-4662.
DOI https://doi.org/ 10.1055/s-0039-1688496. ISSN 0094-6176. 


\section{Conflict of Interest}

None declared.

\section{References}

1 Trousseau A. Phlegmasia alba dolens. In: Clinique Medicale de l'Hotel-Dieu de Paris. Vol. 3. Paris: JB Ballilere et Fils; 1865:654-712

2 Billroth T. Pathology and therapeutics, in fifty lectures. 1871. Clin Orthop Relat Res 2003;(408):4-11

3 Mahajan A, Brunson A, White R, Wun T. The epidemiology of cancer associated venous thromboembolism: an update. Semin Thromb Hemost 2019;45(04):321-325

4 Czap AL, Becker A, Wen PY. Thrombotic complications in gliomas. Semin Thromb Hemost 2019;45(04):326-333

5 Riedl J, Ay C. Venous thromboembolism in brain tumors: risk factors, molecular mechanisms and clinical challenges. Semin Thromb Hemost 2019;45(04):334-341
6 Levi M. Disseminated intravascular coagulation in cancer - an update. Semin Thromb Hemost 2019;45(04):342-347

7 Weitz IC. Thrombotic microangiopathy in cancer. Semin Thromb Hemost 2019;45(04):348-353

8 Walsh M, Moore H, Moore EE, et al. Use of viscoelastography in cancer-associated thrombosis: a review. Semin Thromb Hemost 2019;45(04):354-372

9 Tawil N, Bassawon R, Rak J. Oncogenes and clotting factors - the emerging role of tumor cell genome and epigenome in cancer associated thrombosis. Semin Thromb Hemost 2019;45(04):373-384

10 Hisada Y, Mackman N. Tissue factor and cancer: regulation, tumor growth and metastasis. Semin Thromb Hemost 2019;45(04):385-395

11 Rondon AMR, Kroone C, Kapteijn M, Versteeg HH, Buijs JT. Role of tissue factor in tumor progression and cancer-associated thrombosis. Semin Thromb Hemost 2019;45(04):396-412

12 Kwaan HC, Lindholm PF. Fibrin and fibrinolysis in cancer. Semin Thromb Hemost 2019;45(04):413-422 